\title{
Efeitos sobre biomarcadores hepáticos e o consumo alimentar de ratos Wistar suplementados com Whey Proteins
}

\author{
Effects on liver biomarkers and food consumption of Wistar rats supplemented with Whey Proteins \\ Efectos sobre los biomarcadores hepáticos y el consumo de alimentos de los ratones Wistar
}

complementadas con Proteínas De Suero

Recebido: 13/09/2021 | Revisado: 19/09/2021 | Aceito: 20/09/2021 | Publicado: 21/09/2021

\author{
Anne Karynne da Silva Barbosa \\ ORCID: https://orcid.org/0000-0002-5993-8453 \\ Universidade Federal do Maranhão, Brasil \\ E-mail: karynnenutri@gmail.com \\ Antonio Coppi Navarro \\ ORCID: https://orcid.org/0000-0001-8113-4489 \\ Universidade Federal do Maranhão, Brasil \\ E-mail: ac-navarro@uol.com.br \\ Bruno Araújo Serra Pinto \\ ORCID: https://orcid.org/0000-0003-3595-0578 \\ Universidade Federal do Maranhão, Brasil \\ E-mail: bruno.pinto@ufma.br \\ Francisco Navarro \\ ORCID: https://orcid.org/0000-0002-8475-4285 \\ Universidade Federal do Maranhão, Brasil \\ E-mail: francisconavarro@uol.com.br
}

\begin{abstract}
Resumo
Objetivo: O presente estudo objetivou verificar se o consumo de dosagens mais altas de whey proteins apresentam alterações nos biomarcadores hepáticos e no consumo de ração em ratos Wistar sedentários comparado a dosagens mais baixas. Materiais e Métodos: Trata-se de um estudo experimental, o estudo foi realizado com 32 ratos que foram alocados em quatro grupos, sendo os grupos: $\mathrm{C}$ - controle não suplementado $(\mathrm{n}=10)$, W2 - suplementado com $2 \mathrm{~g} / \mathrm{kg} / \mathrm{dia}(\mathrm{n}=10)$, W4 - suplementado com 4g/kg/dia $(\mathrm{n}=7)$, W6 - suplementado com $6 \mathrm{~g} / \mathrm{kg} / \mathrm{dia}(\mathrm{n}=5)$ através de gavagem e suplementados com whey proteins. Serão analisados os biomarcadores Bilirrubina e Albumina. Resultados: Em relação as proteínas totais foram encontradas diferenças significativas entre os grupos C e W6 $(\mathrm{p}=0,0282)$ e entre os grupos W2 e W6 $(\mathrm{p}=0,0054)$. Para a Bilirrubina foram encontradas diferenças significativas apenas entre os grupos W2 e W6 ( $\mathrm{p}=0,0213)$. Conclusão: Os achados deste estudo sugerem que doses de 2, 4 e $6 \mathrm{~g} / \mathrm{kg} /$ dia de whey proteins não influenciam na alteração dos biomarcadores hepáticos, constituindo-se em um suplemento hepatoprotetor e que conforme aumenta a dosagem de suplementação ocorre redução no consumo de ração, sugerindo que a suplementação com whey proteins pode regular a ingestão de alimentos dos ratos.
\end{abstract}

Palavras-chave: Proteínas; Fígado; Billirubina; Albumina.

\begin{abstract}
Aim: The present study aimed to verify whether the consumption of higher doses of whey proteins present changes in liver biomarkers and in the feed intake in sedentary Wistar rats compared to lower doses. Materials and Methods: This is an experimental study, the study was carried out with 32 rats that were allocated in four groups: C - nonsupplemented control $(\mathrm{n}=10), \mathrm{S} 2$ - supplemented with $2 \mathrm{~g} / \mathrm{kg} /$ day $(\mathrm{n}=10), \mathrm{S} 4$ - supplemented with $4 \mathrm{~g} / \mathrm{kg} / \mathrm{day}(\mathrm{n}=7)$, S6 - supplemented with $6 \mathrm{~g} / \mathrm{kg} / \mathrm{day}(\mathrm{n}=5)$ by gavage and supplemented with whey proteins. Bilirubin and Albumin biomarkers will be analyzed. Results: Regarding total proteins, significant differences were found between groups $\mathrm{C}$ and W6 $(\mathrm{p}=0.0282)$ and between groups W2 and W6 $(\mathrm{p}=0.0054)$. For Bilirubin significant differences were found only between groups W2 and W6 $(\mathrm{p}=0.0213)$. Main Conclusions: The findings of this study suggest that doses of 2 , 4 and $6 \mathrm{~g} / \mathrm{kg} /$ day of whey proteins do not influence the alteration of liver biomarkers, constituting a hepatoprotective supplement and as the dosage of supplementation increases, there is a reduction in feed consumption, suggesting that whey protein supplementation may regulate rat food intake.
\end{abstract}

Keywords: Proteins; Liver; Bilirubin; Albumin.

\section{Resumen}

Objetivo: El presente estudio tuvo como objetivo verificar si el consumo de dosis más altas de proteínas de suero presenta cambios en los biomarcadores hepáticos y en la ingesta de alimento en ratas Wistar sedentarias en 
comparación con dosis más bajas. Materiales y Métodos: Se trata de un estudio experimental, el estudio se realizó con 32 ratas que se dividieron en cuatro grupos, siendo los grupos: $\mathrm{C}$ - control no suplementado $(\mathrm{n}=10)$, W2 suplementado con $2 \mathrm{~g} / \mathrm{kg} /$ día $(\mathrm{n}=10)$, W4 - suplementado con $4 \mathrm{~g} / \mathrm{kg} / \mathrm{dí}$ ( $\mathrm{n}=7)$, W6 - suplementado con $6 \mathrm{~g} / \mathrm{kg} /$ día $(\mathrm{n}=5)$ por sonda y suplementado con proteínas de suero. Se analizarán los biomarcadores de bilirrubina y albúmina. Resultados: Respecto a las proteínas totales, se encontraron diferencias significativas entre los grupos $\mathrm{C}$ y W6 $(\mathrm{p}=0.0282)$ y entre los grupos W2 y W6 $(\mathrm{p}=0.0054)$. Para la bilirrubina, solo se encontraron diferencias significativas entre los grupos W2 y W6 ( $\mathrm{p}=0.0213)$. Conclusión: Los hallazgos de este estudio sugieren que dosis de 2,4 y $6 \mathrm{~g} / \mathrm{kg} /$ día de proteínas de suero de leche no influyen en el cambio de biomarcadores hepáticos, constituyendo un suplemento hepatoprotector y que a medida que aumenta la dosis de suplementación se produce una reducción de el consumo de dieta, lo que sugiere que la suplementación con proteínas de suero puede regular la ingesta de alimentos en ratones.

Palabras clave: Proteínas; Hígado; Billirrubina; Albúmina.

\section{Introdução}

As proteínas são compostas da combinação de 20 aminoácidos, a sequência destes aminoácidos é que definem as principais funções, quer sejam, transporte, regulação, estruturais ou de defesa (Lehninger et al., 2006). Whey proteins apresentam em sua composição, quase todos os aminoácidos essenciais, excluindo apenas os aromáticos, não se mostram de forma frequente, porém atendem as necessidades nutricionais de todas as idades dos seres humanos (Sgarbieri, 2004).

Aponta-se que whey proteins tem maior taxa de absorção, quando comparadas com outras, como a caseína, essa assimilação de forma rápida faz com que as concentrações plasmáticas dos aminoácidos, culminem em valores altos logo após o seu consumo no organismo humano (Dangin et al., 2001; Kerasioti et al., 2018). O consumo de whey proteins logo após a realização de exercícios, diminui o consumo de energia na refeição subsequente, aumentando o teor de massa muscular e diminuindo a gordura corporal (Monteyne et al., 2016).

Comparando as whey proteins com outras proteínas, observa-se que elas têm uma maior taxa de absorção no trato gastrintestinal, e promove maior estimulação de síntese proteica (Poortmans et al., 2012). Em dietas contendo whey proteins, o teor de concentração plasmática de citocinas e os marcadores de lesão hepática são menores, do que aquelas que contêm outros tipos de proteína como a caseína (Kume et al., 2006).

Estudos associando Whey proteins com lesões hepáticas induzidas (isquemia e reperfusão) tem mostrado que as proteínas do soro do leite têm efeito hepatoprotetores, prevenindo o estresse oxidativo, e diminuindo a ocorrência de citocinas pró-inflamatórias, e a infiltração de células inflamatórias, constituindo em um alimento imunonutricional (Nii et al., 2014; Chaves et al., 2018; Al-Dhuayan, 2018).

Mesmo com inúmeros estudos trazendo os benefícios de Whey proteins, outro estudo encontrou efeitos colaterais associados entre a suplementação de Whey proteins e o fígado, analisaram os biomarcadores de inflamação e estresse oxidativo e encontraram que a suplementação de Whey proteins concentrado aumentou a indução do estresse oxidativo hepático e alterou a morfologia dos hepatócitos nos ratos, porém cabe ressaltar que a dosagem utilizada neste estudo foi diferente das dosagens utilizadas nos demais estudos (Gamdzyk et al., 2018).

O presente estudo objetivou verificar se o consumo de dosagens mais altas de whey proteins apresentam alterações nos biomarcadores hepáticos e no consumo de ração em ratos Wistar sedentários comparado com dosagens mais baixas.

\section{Metodologia}

No presente estudo foi adotado delineamento de pesquisa experimental com grupos randomizados (Hoerauf et al., 2019). A realização da pesquisa experimental aconteceu no Biotério Setorial da Universidade Federal do Maranhão-UFMA, em São Luís-MA. 
O protocolo experimental foi aprovado pelo Comitê de Ética no uso de animais (CEUA) através do protocolo de número 23115.001161/2017-85 da Universidade Federal do Maranhão-UFMA.

O presente estudo foi realizado com 32 Rattus novergicus albinus machos da linhagem Wistar com idade inicial de 60 dias e massa corporal aproximada de $286 \mathrm{~g} \pm 31,01$.

Os 32 ratos foram alocados em quatro grupos, sendo os grupos: C - controle não suplementado (n=10), S2 suplementado com $2 \mathrm{~g} / \mathrm{kg} / \mathrm{dia}(\mathrm{n}=10)$, S4 - suplementado com 4g/kg/dia ( $\mathrm{n}=7)$, S6 - suplementado com $6 \mathrm{~g} / \mathrm{kg} / \mathrm{dia}(\mathrm{n}=5)$.

Os ratos permaneceram em condições higiênicas em gaiolas coletivas, mantidos em uma sala climatizada com controle de temperatura entre $24^{\circ} \mathrm{C}$ a $28^{\circ} \mathrm{C}$, e ciclo alternado de claro/escuro de 12 horas. Foram alimentados com ração balanceada padrão para roedores e água ad libitum. As gavagens foram realizadas diariamente durante as doze semanas do experimento, correspondendo a dosagem específica para cada grupo, sendo de 2,4 e 6g/kg/dia.

Vinte e quatro horas após os procedimentos experimentais finais e com jejum de 12 horas, os ratos foram eutanasiados através de injeção intraperitoneal com cetamina $(70 \mathrm{mg} / \mathrm{kg})$ e xilasina $(10 \mathrm{mg} / \mathrm{kg})$ de acordo com protocolo já validado na literatura (Neves et al., 2013).

As análises de Billirubina, Proteínas totais e Albumina foram realizadas seguindo o método reação de ponto final com kits Labtest.

Todas as variáveis foram testadas quanto à distribuição da normalidade utilizando o teste de Shapiro-Wilk. Para a comparação entre medidas repetidas entre as semanas em cada grupo separadamente, foi aplicado o teste de ANOVA one way post-hoc de Tukey adotando os valores significativos de $p<0,05$. Para a comparação de uma variável intergrupos ao longo do tempo, foi utilizado o teste ANOVA two way post-hoc de Tukey adotando valores significativos de $p<0,05$. O software que foi utilizado para as análises foi o Graphpad Prism® versão 8.

Quadro 1. Composição da ração ofertada durante o experimento.

\begin{tabular}{|c|c|c|c|}
\hline & \multicolumn{3}{|c|}{ Quantidade por kg } \\
\hline Nutriente & $\mathbf{g} / \mathbf{m g} / \mathbf{k g}$ & Nutriente & $\mathbf{g} / \mathbf{m g} / \mathbf{k g}$ \\
\hline Umidade & $120 \mathrm{~g}$ & Pantoten de cálcio & $112 \mathrm{mg}$ \\
\hline Proteína bruta & $220 \mathrm{~g}$ & Ácido fólico & $6 \mathrm{mg}$ \\
\hline Extrato etéreo & $40 \mathrm{~g}$ & Biotina & $0,26 \mathrm{mg}$ \\
\hline Material mineral & $90 \mathrm{~g}$ & Colina & $2.400 \mathrm{mg}$ \\
\hline Fibra bruta & $70 \mathrm{~g}$ & Sódio & $2.700 \mathrm{mg}$ \\
\hline Cálcio & $10-14 \mathrm{~g}$ & Ferro & $50 \mathrm{mg}$ \\
\hline Fósforo & $8.000 \mathrm{mg}$ & Manganês & $60 \mathrm{mg}$ \\
\hline Vitamina A & $25.500 \mathrm{UI}$ & Zinco & $60 \mathrm{mg}$ \\
\hline Vitamina D3 & $2.100 \mathrm{UI}$ & Cobre & $10 \mathrm{mg}$ \\
\hline Vitamina E & $60 \mathrm{UI}$ & Iodo & $2 \mathrm{mg}$ \\
\hline Vitamina K3 & $12,5 \mathrm{mg}$ & Selênio & $0,05 \mathrm{mg}$ \\
\hline Vitamina B1 & $14,4 \mathrm{mg}$ & Cobalto & $1,5 \mathrm{mg}$ \\
\hline Vitamina B2 & $11 \mathrm{mg}$ & Fluór & $80 \mathrm{mg}$ \\
\hline Vitamina B6 & $12 \mathrm{mg}$ & Lisina & $14 \mathrm{~g}$ \\
\hline Vitamina B12 & $60 \mathrm{mcg}$ & Metionina & $5.000 \mathrm{mg}$ \\
\hline Niacina & $60 \mathrm{mg}$ & Aditivo BHT & $100 \mathrm{mg}$ \\
\hline
\end{tabular}

Fonte: Autores (2021).

No Quadro 1 estão dispostas as informações acerca da ração ofertada para os animais do experimento, sendo uma ração balanceada padrão para roedores. 


\section{Resultados}

\section{Consumo relativo de ração}

Figura 1 - Consumo relativo de ração intergrupos.



\section{Semanas do experimento}

Fonte: Autores (2021).

Observou-se que houve diferença significativa apenas entre os grupos C e W2 (p=0,0093), entre C e W4 ( $\mathrm{p}=0,0381)$, os demais grupos não apresentaram diferença significativa, entre os grupos C e W6 ( $\mathrm{p}=0,9976)$, entre os grupos W2 e W4 ( $\mathrm{p}=0,9973)$, entre os grupos W2 e W6 ( $\mathrm{p}=0,1253)$, entre os grupos W4 e W6 ( $\mathrm{p}=0,2148)$.

De acordo com a Figura 1, pode-se observar que os grupos W2 e controle apresentaram consumo mais baixo quando comparados ao grupo W6 no início do protocolo e ao final do experimento apresentaram consumo mais elevado, também foi observado que o consumo do grupo W6 que iniciou com maior ingesta de ração, onde o grupo W6 apresentou um pico de maior consumo na semana 10, ou seja, com a suplementação de whey proteins interferiu na ingestão de ração, e houve queda brusca no consumo pelos grupos W4 e W6 na semana 12.

Observa-se que os grupos que foram suplementados com dosagens mais elevadas de whey proteins (sendo as dosagens de 4 e 6g/kg/dia), obtiveram padrão de redução no consumo de ração, sendo um fator positivo, visto que o alto consumo de ração poderia desencadear em aspectos nutricionais diversos, incluindo alterações de biomarcadores hepáticos. 


\section{Biomarcadores hepáticos}

Bilirrubina

Figura 2 - Valores de análises de Bilirrubina intergrupos.

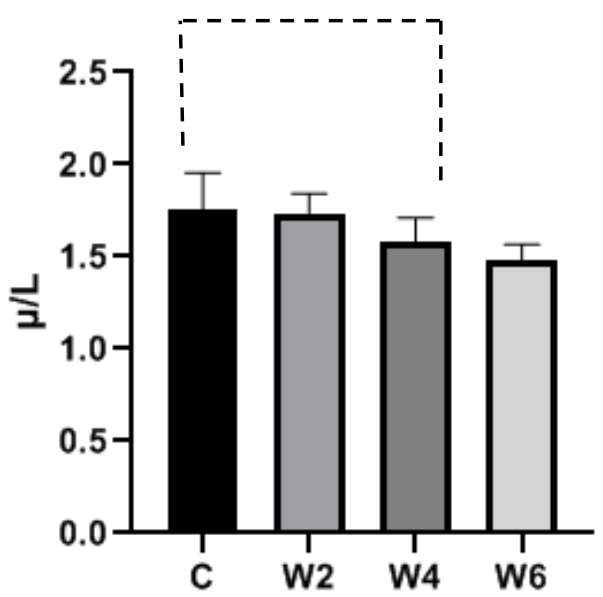

Fonte: Autores (2021).

Foram encontradas diferenças significativas apenas entre os grupos W2 e W6 (p=0,0213), nos demais grupos não foram encontradas diferenças significativas, entre C e W2 (p=0,9936), entre C e W4 (p=0,1733), entre C e W6 (p=0,0647), entre W2 e W4 ( $p=0,2423)$, entre W4 e W6 $(p=0,7383)$.

Conforme descrito na Figura 2, observa-se que os grupos C e W2 apresentaram valores mais altos de bilirrubina quando comparados aos demais grupos, e que conforme o aumento da dosagem suplementada houve redução na concentração de bilirrubina sérica.

Proteínas totais

Figura 3 - Valores de análises de Proteínas totais intergrupos.



Fonte: Autores (2021). 
Foram encontradas diferenças significativas entre os grupos C e W6 $(\mathrm{p}=0,0282)$ e entre os grupos W2 e W6 $(\mathrm{p}=0,0054)$, nos demais grupos não foram encontradas diferenças significativas, entre C e W2 ( $\mathrm{p}=0,4747)$, entre C e W4 $(\mathrm{p}=0,3162)$, entre W2 e W4 ( $\mathrm{p}=0,6194)$, entre W4 e W6 ( $\mathrm{p}=0,3323)$.

De acordo com a Figura 3 observa-se que houve redução de proteínas totais conforme o aumento da dosagem de suplementação de whey proteins, posto que os grupos C e W2 apresentaram maiores valores, respectivamente. O grupo W6 apresentou o menor valor desse biomarcador.

Albumina

Figura 4 - Valores de análises de Albumina intergrupos.

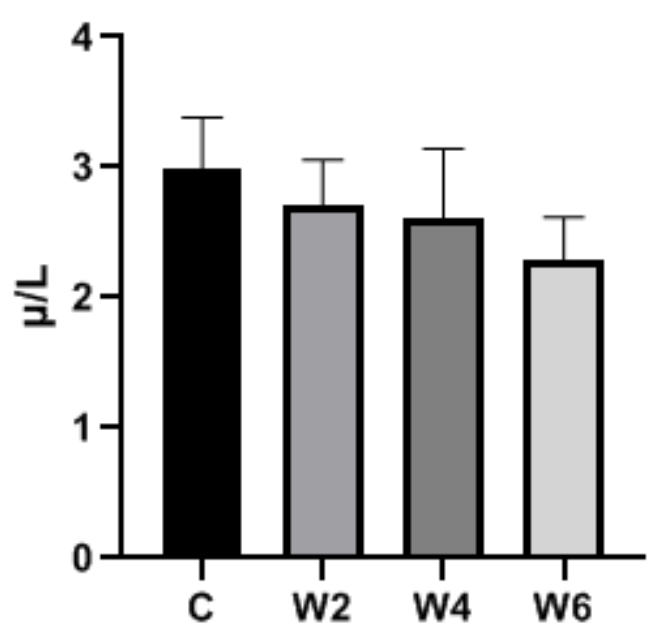

Fonte: Autores (2021).

Não foram encontradas diferenças significativas entre os grupos, entre os grupos C e W2 ( $\mathrm{p}=0,1985)$, entre os grupos C e W4 ( $\mathrm{p}=0,2635)$, entre os grupos C e W6 ( $\mathrm{p}=0,1557)$, entre os grupos W2 e W4 ( $\mathrm{p}=0,8258)$, entre os grupos W2 e W6 $(\mathrm{p}=0,4168)$, entre os grupos W4 e W6 ( $\mathrm{p}=0,8015)$.

Conforme descrito na Figura 4, os valores de albumina foram reduzidos conforme o aumento da suplementação de dosagem de whey proteins, sendo que o grupo C e W2 apresentaram as maiores concentrações, respectivamente.

De acordo com o observado nos biomarcadores hepáticos, observou-se que conforme foram aumentadas as dosagens de suplementação, sendo nas dosagens de 4 e $6 \mathrm{~g} / \mathrm{kg} / \mathrm{dia}$, as concentrações séricas dos biomarcadores bilirrubina, proteínas totais e albumina foram reduzidas, whey proteins se constituindo em um hepatoprotetor. 7

\section{Discussão}

Em relação ao biomarcador de Bilirrubina, os resultados obtidos no presente estudo corroboram com o estudo de Haraguchi et al., (2009) com 32 ratos machos Fisher, divididos em 4 grupos, no qual os autores encontraram que os grupos que receberam as dietas com whey proteins não aumentaram a atividade da Bilirrubina, sendo um efeito benéfico para o fígado.

Corroborando também com uma pesquisa de Kume et al., (2006) com ratos sprague-dawley machos onde observaram níveis reduzidos de biomarcadores hepáticos, tais como albumina e bilirrubina, em dosagens de caseína e whey proteins, sendo que a dosagem ofertada de whey proteins foi hepatoprotetora, posto que não causou danos a função hepática dos ratos. 
Corroborando com a pesquisa de Xu et al., (2009) sobre a indução de injúria hepática, onde os autores não encontraram diferença significativa nas concentrações de bilirrubina e albumina nos dois grupos com injúria hepática, comparados ao grupo controle.

Em relação ao biomarcador Albumina, corroboram com os estudos de Kume et al., (2006) e Haraguchi et al., (2009), onde os autores encontraram que os grupos que receberam as dietas com whey proteins não aumentaram a atividade da albumina, e em alguns grupos foram observados a redução desse biomarcador, se constituindo em um efeito benéfico para o fígado.

O presente estudo também corrobora com os achados de um estudo de Jahromi et al., (2018) com ratos e a função hepática onde não foram encontradas diferenças significativas dos biomarcadores albumina, bilirrubina e proteínas totais no grupo controle sobre a toxicidade hepática, porém os autores não utilizaram whey proteins como suplementação.

Em relação ao consumo relativo de ração foram encontradas diferenças significativas apenas entre os grupos C e W2 ( $\mathrm{p}=0,0093)$, entre C e W4 ( $\mathrm{p}=0,0381$ ), os demais grupos não apresentaram diferença significativa, corroborando com o estudo de Freudenberg et al., (2012) com camundongos onde os autores encontraram uma ingestão menor de ração nos grupos que foram suplementados com whey proteins, cabe ressaltar que mesmo o estudo sendo realizado com camundongos em uma duração de tempo maior de experimento do que a duração do presente estudo ambos tiveram resultados semelhantes. Corroborando também com o estudo de Zapata et al., (2017) com ratos por 8 semanas, onde observaram mudanças de redução no consumo de ração pelos ratos suplementados com whey proteins.

Corroborando também com um estudo de Zhou et al., (2011) com ratos onde os autores observaram que a suplementação com whey proteins por 5 semanas colaborou na redução da ingestão de ração. Também corrobora com o estudo de Wada et al., (2019) com ratos wistar machos, os quais nos resultados foram observados que o consumo de ração foi maior a ingesta no grupo controle quando comparado aos grupos suplementados com aminoácidos.

O presente estudo difere do estudo de Haraguchi et al., (2009) com 32 ratos machos Fisher, com dietas com proteína do soro do leite e com dietas ricas em gorduras, pois os autores encontraram menor consumo de alimento nos grupos que receberam as dietas ricas em gordura, apesar de maior ganho de peso por esses grupos.

O presente estudo também difere do estudo de Chen et al., (2014) com ratos treinados, no qual os autores não encontraram diferenças no consumo de água e ração entre os grupos suplementados com whey proteins, e isso pode ser devido ao fato de que no presente estudo não foram adotados protocolos de treinos.

\section{Conclusão}

Os achados deste estudo apresentam a sugestão de que doses de 2,4 e $6 \mathrm{~g} / \mathrm{kg} / \mathrm{dia}$ de whey proteins não influenciam na alteração dos biomarcadores hepáticos bilirrubina, albumina e proteínas totais, se constituindo em um suplemento hepatoprotetor, respondendo ao objetivo proposto. Observou-se também sobre o consumo de ração onde os grupos que receberam suplementação com whey proteins apresentaram redução do consumo de ração, esta diminuição na ingestão sugere que a suplementação com whey proteins pode regular a ingestão de alimentos dos ratos. Os dados apresentados no presente estudo quanto aos valores de análises bioquímicas dos biomarcadores de dano hepático apresentam maiores valores para os grupos controle e o que foi suplementado com $2 \mathrm{~g} / \mathrm{kg} / \mathrm{dia}$ de whey proteins, quando comparado aos demais grupos, onde foram encontrados que conforme a dosagem da suplementação aumentou tanto as concentrações dos biomarcadores hepáticos quanto a ingestão de ração foram reduzidos. 


\section{Referências}

Al-Dhuayan, I. S. (2018). Possible protective role of whey protein on the rat's liver tissues treated with nandrolone decanoate. Pakistan journal of biological sciences. $21(6): 262-274$.

Chaves, F. M., Baptista, I. L., Simabuco, F. M., Quaresma, P. G. F., Pena, F. L., Bezerra, R. M. N., Pauli, J. R., Cunha, D. T., Campos-Ferraz, P. L., \& Antunes, A. E. C. (2018). High-intensity-exercise-induced intestinal damage is protected by fermented milk supplemented with whey protein, probiotic and pomegranate (Punica granatum L.). British Journal of nutrition. 119:896-909.

Chen, W. C., Huang, W. C., Chiu, C. C., Chang, Y. K., \& Huang, C. C. (2014). Whey protein improves exercise and biochemical profiles in trained mice. Medicine and science in sports and exercise. 46 (8):1517-1524,

Dangin, M., Boirie, Y., Garcia-Rodenas, C., Gachon, P., Fauquant, J., Callier, P., Ballèvre, O., \& Beaufrère, B. (2001) The digestion rate of protein is an independent regulation factor of postprandial protein retention. Am J Physiol Endocrinol Metab. 280:340-342.

Freudenberg, A., Petzke, K. J., \& Klaus, S. (2012). Comparison of high-protein diets and leucine supplementation in the prevention of metabolic syndrome and related disorders in mice. Journal of nutritional biochemistry. 23:524-1530.

Gamdzyk, M. Z., Maciejczyk, M., Zalewska, A., Ustymowick, K. G., Tokajuk, A., \& Car, H. (2018). Whey protein concentrate WPC-80 intensifies glycoconjugate catabolism and induces oxidative stress in the liver of rats. Nutrients. 10 (1178):2-18.

Haraguchi, F. K., Pedrosa, M. L., Paula, H., Santos, R. C., \& Silva, M. E. Influence of whey protein on liver enzymes lipid profile and bone formation of hypercholesterolemic rats. Revista de Nutrição. Campinas. 22 (4):517-525.

Hoerauf, J. M., Moss, A. F., Bustamante, A. F., \& Bartels, K. (2019). Study design rigor in animal-experimental research published in Anesthesia journals. Anesth Analg. 126 (1):217-222.

Jahromi, H. K., Pourahmad, M., Abedi, H. A., Karimi, M., \& Jahromi, Z. K. (2018). Protective effects of salep against isoniazid liver toxicity in wistar rats. $J$ Tradit Complement Med. 8 (1):239-243.

Kerasioti, E., Stagos, D., Tsatsakis, A. M., Spandidos, D. A., Taitzoglou, J., \& Kouretas, T. (2018). Effects of sheep/goat whey protein dietary supplementation on the redox status of rats. Molecular Medicine Reports. 17: 5774-5781.

Kume, H., Okazaki, K., \& Sasaki, H. (2006). Hepatoprotective effects of whey protein on D-galactosamine-induced hepatitis and liver fibrosis in rats. Biosciense, Biotechnology, Biochemistry. 70 (5):1281-1285.

Lehninger, A. L., Nelson, D. L., \& Cox, M. M. (2006). Princípios da bioquímica. (4a ed.), Sarvier.

Monteyne, A., Martin, A., Jacson, L., Corrigan, N., Stringer, E., Newey, J., Rumbold, P. L. S., Stevenson, E. J., \& James, L. J. (2016). Whey protein consumption after resistance exercise reduces energy intake at a post-exercise meal. European Journal of Nutrition. 57: 1-8. Springer Nature. http://dx.doi.org/10.1007/s00394-016-1344-4.

Neves, S. M. P., Mancini Filho, J., \& Menezes, E. W. (2009). Manual de cuidados e procedimentos com animais de laboratório do biotério de produção e experimentação da FCF-IQ/USP. 2013. São Paulo: FCF-IQ/USP. 216.

Nii, A., Utsunomiya, T., Shimada, M., Ikegami, T., Ishibashi, H., Imura, S., Morine, Y., Ikemoto, T., Sasaki, H., \& Kawashima, A. (2014). A hydrolyzed whey peptide-based diet ameriolates hepatic ischemia-reperfusion injury in the rat nonalcoholic fatty liver. Surg Today. 44:2354-2360.

Poortmans, J. R., Carpentier, A., Pereira-Lancha, R. O., \& Lancha Junior, A. (2012). Protein turnover, amino acid requirements and recommendations for athletes and active populations. Braz J Med Biol Res. 45 (10):875-890.

Sgarbieri, V. C. Propriedades fisiológicas-funcionais das proteínas do soro de leite. (2004). Rev. Nutr. 17 (4):397-409.

Wada, Y., Xijier, N. S., Komatsu, Y., Tsuda, M., Kitamura, Y., Izumi, H., Shimizu, T., \& Takeda, Y. (2019). Plasma albumin redox state is responsive to the amino acid balance of dietary proteins in rats fed a low protein diet. Frontiers in nutrition. 6 (12).

Xu, G. S., Liu, H. N., Li, J., Wu, X. L., Dai, X. M., \& Liu, Y. H. (2009). Hepatic injury induced by carbono dioxide pneumoperitoneum in experimental rats. World J Gastroenteterol. 15 (24):3060-3064.

Zapata, R. C., Singh, A., Pezeshki, A., Nibber, T., \& Chelikani, P. K. (2017). Whey protein components - lactoalbumin and lactoferrin - improve energy balance and metabolism. Scientific reports. 7 (1):9917.

Zhou, J., Keenan, M. K., Losso, J. N., Raggio, A. M., Shen, L., McCutcheon, K. L., Tulley, R. T., Blackman, M. R., \& Martin, R. J. (2011). Dietary whey protein decreases food intake and body fats in rats. Obesity. 19 (8):1568-1573. 